\title{
Advanced Glycated apoA-IV Loses Its Ability to Prevent the LPS-Induced Reduction in Cholesterol Efflux-Related Gene Expression in Macrophages
}

\author{
Ligia Shimabukuro Okuda $\mathbb{D}^{1},{ }^{1}$ Rodrigo Tallada Iborra, ${ }^{1,2}$ Paula Ramos Pinto, ${ }^{1}$ \\ Ubiratan Fabres Machado $₫{ }^{3}$ Maria Lucia Corrêa-Giannella, ${ }^{4,5}$ Russell Pickford, ${ }^{6}$ \\ Tom Woods, ${ }^{7}$ Margaret Anne Brimble, ${ }^{7}$ Kerry-Anne Rye, ${ }^{8}$ and Marisa Passarelli $\mathbb{D}^{1,5}$ \\ ${ }^{1}$ Laboratório de Lípides (LIM 10), Hospital das Clínicas (HCFMUSP), Faculdade de Medicina da Universidade de São Paulo, \\ São Paulo, Brazil \\ ${ }^{2}$ Universidade São Judas Tadeu, São Paulo, Brazil \\ ${ }^{3}$ Department of Physiology and Biophysics, Institute of Biomedical Sciences, University of São Paulo, São Paulo, Brazil \\ ${ }^{4}$ Laboratório de Carboidratos e Radioimunoensaio (LIM 18), Hospital das Clínicas (HCFMUSP), Faculdade de Medicina da \\ Universidade de São Paulo, São Paulo, Brazil \\ ${ }^{5}$ Programa de Pós-Graduação em Medicina, Universidade Nove de Julho, São Paulo, Brazil \\ ${ }^{6}$ Bioanalytical Mass Spectrometry Facility, University of New South Wales, Sydney, Australia \\ ${ }^{7}$ School of Chemical Sciences, University of Auckland, Auckland, New Zealand \\ ${ }^{8}$ Lipid Research Group, School of Medical Sciences, University of New South Wales, Sydney, Australia
}

Correspondence should be addressed to Marisa Passarelli; m.passarelli@fm.usp.br

Received 18 October 2019; Revised 6 December 2019; Accepted 21 December 2019; Published 14 January 2020

Academic Editor: Elaine Hatanaka

Copyright (c) 2020 Ligia Shimabukuro Okuda et al. This is an open access article distributed under the Creative Commons Attribution License, which permits unrestricted use, distribution, and reproduction in any medium, provided the original work is properly cited.

\begin{abstract}
We addressed how advanced glycation (AGE) affects the ability of apoA-IV to impair inflammation and restore the expression of genes involved in cholesterol efflux in lipopolysaccharide- (LPS-) treated macrophages. Recombinant human apoA-IV was nonenzymatically glycated by incubation with glycolaldehyde (GAD), incubated with cholesterol-loaded bone marrow-derived macrophages (BMDMs), and then stimulated with LPS prior to measurement of proinflammatory cytokines by ELISA. Genes involved in cholesterol efflux were quantified by RT-qPCR, and cholesterol efflux was measured by liquid scintillation counting. Carboxymethyllysine (CML) and pyrraline (PYR) levels, determined by Liquid Chromatography-Mass Spectrometry (LC-MS/MS), were greater in AGE-modified apoA-IV (AGE-apoA-IV) compared to unmodified-apoA-IV. AGE-apoA-IV inhibited expression of interleukin 6 (Il6), TNF-alpha (Tnf), IL-1 beta (Illb), toll-like receptor 4 (Tlr4), tumor necrosis factor receptor-associated factor 6 (Traf6), Janus kinase 2/signal transducer and activator of transcription 3 (Jak2/Stat3), nuclear factor kappa B (Nfkb), and AGE receptor 1 (Ddost) as well as IL-6 and TNF-alpha secretion. AGE-apoA-IV alone did not change cholesterol efflux or ABCA-1 levels but was unable to restore the LPS-induced reduction in expression of Abca1 and Abcg1. AGE-apoA-IV inhibited inflammation but lost its ability to counteract the LPS-induced changes in expression of genes involved in macrophage cholesterol efflux that may contribute to atherosclerosis.
\end{abstract}

\section{Introduction}

The inverse relationship between plasma HDL-cholesterol (HDL-C) levels and cardiovascular disease (CVD) risk is well established in epidemiological studies [1]. Nonetheless, many clinical trials of agents that increase plasma HDL-C and Mendelian randomization studies have failed to demonstrate that increasing HDL-C levels reduces CV endpoints [2-4]. These negative outcomes have led to the conclusion that HDL functionality may be a better marker of the 
cardioprotective properties of HDL than measurement of plasma HDL-C or apoA-I levels $[5,6]$.

HDLs are heterogeneous particles varying in composition and size [7]. The major HDL apolipoprotein is apoA-I, followed by apoA-II and apoA-IV. ApoA-I and apoA-IV both inhibit inflammation, oxidation, platelet aggregation, and thrombosis [8-12]. ApoA-IV also modulates triglyceriderich lipoprotein assembly and metabolism, improves glucose homeostasis, and inhibits food intake [13-19]. ApoA-IV additionally mediates steps of the reverse cholesterol transport (RCT) pathway, where excess cholesterol from the arterial wall is transported to the liver for excretion into bile and feces. This occurs by the interaction of lipid-free apolipoproteins and HDL to the ATP-binding cassette transporters A1 (ABCA-1) and G1 (ABCG-1), activation of lecithin cholesterol acyltransferase (LCAT), activity of cholesteryl ester transfer protein (CETP), and uptake of esterified cholesterol from HDL by the hepatic scavenger receptor B-I (SR-BI) [20-25].

Clinical studies in humans and HDL proteome data have demonstrated an inverse association between plasma apoAIV levels and CVD [26, 27]. In addition, exogenous administration or overexpression of A-IV in apoE knockout mice reduces the atherosclerotic lesion area $[8-10,28,29]$. In this context, apoA-IV is considered a potential therapeutic target for the prevention or treatment of atherosclerosis [30].

Advanced glycation end products (AGEs) are prevalent in diabetes mellitus (DM) and impair HDL functionality $[31,32]$. AGEs are generated when glucose and oxoaldehydes interact nonenzymatically with lysine and arginine residues in the amino terminal domain of proteins such as apolipoproteins. They are also generated by the nonenzymatic interaction of glucose and oxoaldehydes with phospholipids and nucleic acids [33]. AGE formation has also been reported in patients with inflammatory conditions and chronic kidney disease [34]. Exogenous sources of AGEs include food cooked at a high temperature and tobacco [33, 35].

Nonenzymatic glycation of apoA-I reduces HDL function as well as increases coronary artery plaque progression in patients with type 2 diabetes mellitus (T2DM) [36-41]. A recent study demonstrated that the extent of derivatization of apoA-IV by the AGE carboxymethyllysine (CML) is associated with coronary heart disease severity [42].

The present study is concerned with how the modification of apoA-IV by AGEs compromises its capacity to inhibit lipopolysaccharide- (LPS-) induced inflammation and macrophage cholesterol efflux.

\section{Material and Methods}

2.1. Production of Recombinant Human apoA-IV. A vector containing the apoA-IV gene (plasmid pET14b) was inserted into Clear-Coli BL21 (DE3) electrocompetent cells (Lucigen Corporation, Middleton, WI). The $\mathrm{pET}-14 \mathrm{~b}$ vector contained an N-terminal histidine-tag sequence followed by a thrombin cleavage site and three cloning sites as well as the gene for ampicillin resistance. ApoA-IV expression was induced by addition of $1 \mathrm{M}$ isopropyl- $\beta$-D-1-thiogalactopyranoside (IPTG). ApoA-IV was purified using $2 \times 5 \mathrm{~mL}$ His-Trap fast flow columns connected in series to an AKTA FPLC system
(GE Healthcare, Chicago, IL). The histidine-tag was removed by incubation for $24 \mathrm{~h}$ at $37^{\circ} \mathrm{C}$ with thrombin $(2 \mathrm{U} / \mathrm{mg}$ protein). Endotoxin levels of the purified apolipoprotein were measured using a LAL chromogenic endotoxin quantitation kit (Thermo Fisher Scientific, Rockford, IL) and were $\leq 0.5 \mathrm{EU} / \mathrm{mL}$ [43].

2.2. Advanced Glycation of Recombinant apoA-IV. Recombinant apoA-IV was incubated for $24 \mathrm{~h}$ at $37^{\circ} \mathrm{C}$ without (unmodified-apoA-IV) or with $0.25,0.5$, or $1 \mathrm{mM}$ glycolaldehyde (GAD; AGE-apoA-IV) (Sigma-Aldrich, St Louis, MO) in endotoxin-free phosphate buffer (PBS; $\mathrm{NaCl} 137 \mathrm{mmol} / \mathrm{L}$; $\mathrm{Na}_{2} \mathrm{HPO}_{4} 4 \mathrm{mmol} / \mathrm{L} ; \mathrm{KCl} 2 \mathrm{mmol} / \mathrm{L} ; \mathrm{K}_{2} \mathrm{PO}_{4} 1 \mathrm{mmol} / \mathrm{L}$, $\mathrm{pH} 7.4)$, then dialyzed against PBS and filtered $(0.22 \mu \mathrm{m}$ filter). The final concentration of unmodified AGE-apoA-IV was determined using a BCA Protein Assay Kit (Pierce Biotechnology, Rockford, IL).

2.3. Liquid Chromatography-Mass Spectrometry (LCMS/MS). LC-MS/MS was used to determine carboxymethyllysine (CML) and pyrraline (PYR) levels in apoA-IV as previously described [44]. Briefly, unmodified and AGEapoA-IV were concentrated and digested using four different enzymes (pepsin, pronase E, aminopeptidase, and prolidase). Samples were separated and analyzed by high-performance liquid chromatography (HPLC) coupled directly to a TSQ Quantum Access triple quadrupole mass spectrometer (Thermo Fisher Scientific, Bremen, Germany) via an electrospray interface operating in the positive mode. Calibration curves generated with a range of concentrations (0-10 ng of $\mathrm{CML} / \mu \mathrm{L}$ and $0-100 \mathrm{pg}$ of $\mathrm{PYR} / \mu \mathrm{L}$ ) of unlabeled standards and a constant concentration of isotopically labelled standards (ISTD) were used to calculate the amount of CML and PYR in samples.

2.4. Cell Culture. Animal care was performed in accordance to the National Research Council (US) Committee for the Update of the Guide for the Care and Use of Laboratory Animals (2011) and approved by Animal Care and Research Advisory Committee (Faculdade de Medicina da Universidade de Sao Paulo-CEUA 607/1302). Bone marrowderived cells were isolated from wild-type C57BL/6 mice and cultured for 5 days at $37^{\circ} \mathrm{C}$ under $5 \% \mathrm{CO}_{2}$ in $\mathrm{L} 929$ cellconditioning media (NCTC clone 929, code 0188, Cell Bank Rio de Janeiro-BCRJ) containing colony stimulating factor1 (CSF-1) [45]. Differentiated bone marrow-derived macrophages (BMDMs) were loaded with cholesterol by incubation for $24 \mathrm{~h}$ with low-glucose Dulbecco's modified Eagle Medium (DMEM) and acetylated LDL (50 $\mu \mathrm{g}$ of protein/mL) [46]. Unmodified or AGE-apoA-IV (glycated with $1 \mathrm{mM}$ GAD) were then added to the cells at a final concentration of $50 \mu \mathrm{g} / \mathrm{mL}$. After a further $48 \mathrm{~h}$ of incubation, the apoA-IV was removed, and the macrophages were incubated for $24 \mathrm{~h}$ with lipopolysaccharide (LPS) $(1 \mu \mathrm{g} / \mathrm{mL} ; E$. coli serotype 026:B6; Sigma-Aldrich).

The medium was then removed, centrifuged for $10 \mathrm{~min}$ at $453 \mathrm{xg}$ and frozen $\left(-20^{\circ} \mathrm{C}\right)$ until use. The concentrations of interleukin 6 (IL-6) and tumor necrosis factor-alpha (TNF- 


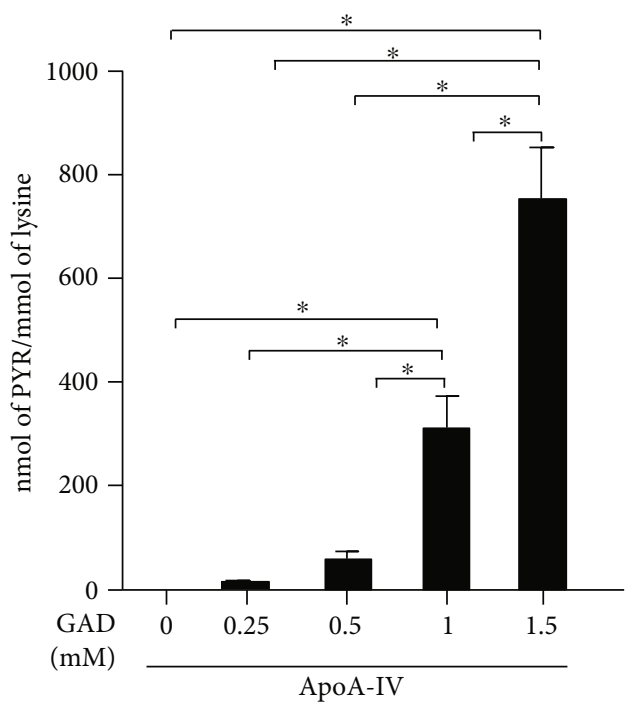

(a)

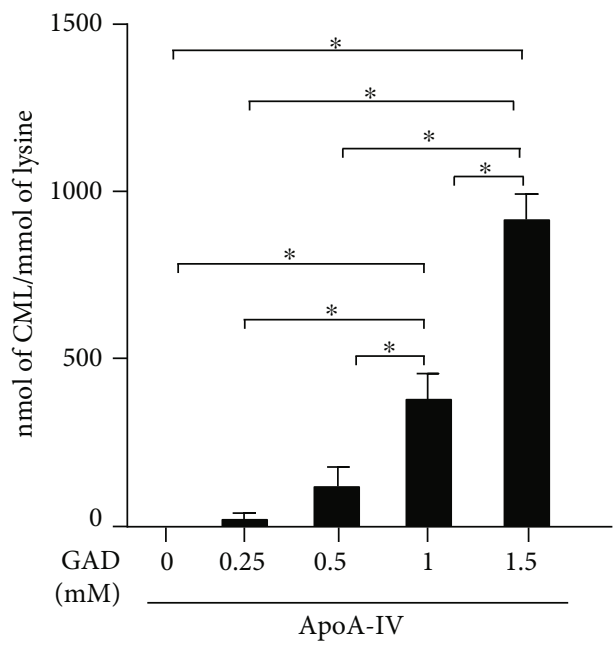

(b)

FIgUre 1: Pyrraline (PYR) and carboxymethyllysine (CML) content in ApoA-IV submitted to in vitro advanced glycation. ApoA-IV was incubated for $24 \mathrm{~h}$, at $37^{\circ} \mathrm{C}$ with different concentrations of glycolaldehyde (GAD). After digestion, samples were analyzed by LC-MS/MS ( $n=9$ ). One-way ANOVA with Tukey's post-test was utilized to compare groups (data from 3 independent experiments; mean \pm SD; ${ }^{*} p<0.0001$ ).

alpha) were determined by ELISA (R\&D System, DuoSet, Minneapolis, MN).

2.5. Cholesterol Efflux Assay. BMDMs were loaded with cholesterol by incubation for $48 \mathrm{~h}$ with acetylated LDL ( $50 \mu \mathrm{g}$ of protein $/ \mathrm{mL})$ and ${ }^{14} \mathrm{C}$-cholesterol $(0.3 \mathrm{uCi} / \mathrm{mL}$, Perkin Elmer, Boston, MA) then incubated with DMEM containing fatty acid-free bovine serum albumin (BSA) for $24 \mathrm{~h}$ to equilibrate cell cholesterol pools. The cells were then incubated for $8 \mathrm{~h}$ with unmodified-apoA-IV or AGE-apoA-IV $(30 \mu \mathrm{g} / \mathrm{mL})$. Radioactivity was measured in the medium and in the cells. The \% cholesterol efflux was calculated as described by Machado et al. [47].

2.6. Analysis of Gene Expression. RNA was isolated following the protocol as described by the manufacturer (RNeasy Mini Kit, Qiagen, Hilden, Germany). Sample integrity and concentration were evaluated using an Agilent Bioanalyzer RNA Kit (Agilent, Santa Clara, CA). cDNA was synthesized from $200 \mathrm{ng}$ of total RNA using High-Capacity RNA-tocDNA Kit (Applied Biosystems, Foster City, CA) then stored at $-20^{\circ} \mathrm{C}$ until use. A StepOne Real Time PCR System and Gene Expression Master Mix (Applied Biosystems) were used for RT-qPCR analysis. The following probes were used (TaqMan): Tnf: Mm00450234_m1, Il6: Mm00450234_m1, Il1b: Mm00434228_m1, Ccl2: Mm00441242_m1, Tlr4: Mm00445273_m1, Myd88: Mm00440338_m1, Traf6: Mm00493836_m1, Nfkb: Mm00481872_s1, Rela: Mm00501346_m1, Jak2: Mm01208489_m1, Stat3: Mm01219775_m1, Ager: Mm01134790_g1, Ddost: Mm00492100_m1, Abca1: Mm00442646_m1, Abcg1: Mm00437390_m1, Scarb1: Mm00450234_m1, Nr1h3: Mm01329744_g1, and Nr1h2: Mm00437265_g1. The relative expression of each gene was normalized to $\beta$-actin (Actb: Mm00607939_s1). Relative quantification of gene expression was performed using StepOne software 2.0 (Applied Biosystems) and the comparative method of cycle threshold (Ct) $(2-\Delta \Delta \mathrm{Ct})[48]$.

2.7. Western Blotting. Cholesterol-loaded BMDMs were pretreated with unmodified or AGE-apoA-IV and then incubated with LPS as described above. Cells were then washed with cold PBS, centrifuged ( $\left.14000 \mathrm{rpm}, 5 \mathrm{~min}, 4^{\circ} \mathrm{C}\right)$ and resuspended in Tris buffered saline (TBS) containing protease inhibitors and preservatives $(1.5 \mathrm{mM}$ aprotinin, $2 \mu \mathrm{M}$ pepstatin, $1 \mu \mathrm{M}$ leupeptin, and $0.1 \mathrm{mM}$ PMSF). The cells were lysed by sonication (12 sec, 5\% amplitude-Branson Sonifier 450, Danbury, CT, USA). The cell membrane fraction was isolated by centrifugation $\left(15 \mathrm{~min}, 14000 \mathrm{rpm}, 4^{\circ} \mathrm{C}\right)$, and the protein concentration was determined by the BCA method (Pierce Biotechnology, Rockford, IL). The samples (50 $\mu \mathrm{g})$ were loaded onto a polyacrylamide gel (6.5\%), electrophoresed for $1.5 \mathrm{~h}$, transferred to a PVDF membrane, and immunoblotted with an antiABCA1 monoclonal antibody (1:50; MABI98-7). The monoclonal antibody to mouse and human ABCA1 (MABI98-7) was generated in rats against the $\mathrm{C}$-terminal peptide CNFAKDQSDDDHLKDLSLHKN and was kindly provided by Professor Shinji Yokoyama (MAB Institute, Japan). Bands were visualized by ECL (WESTAR, Cyanagen, Bologna, Italy). Image capture was performed using ImageQuant 350 (GE Healthcare). Results were expressed in arbitrary units and normalized to beta-actin (Actin-pan antibody 10R-A106A; $1: 1000$, Fitzgerald Industries Int., Acton, MA, USA).

2.8. Statistical Analysis. Statistical analysis was performed using GraphPad Prism 6.05 (GraphPad Software, Inc.). One way ANOVA with Tukey's post-test or Student's $t$ tests were used to compare groups. All situations with a descriptive level of significance of $<5 \%$ were considered as significant. 


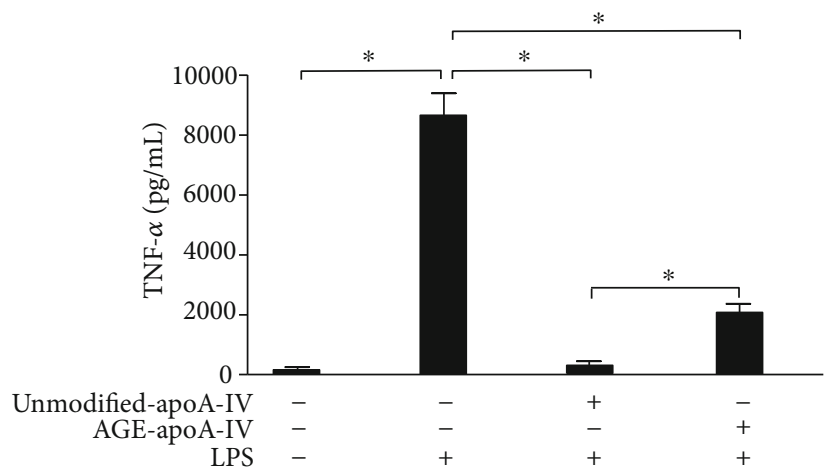

(a)

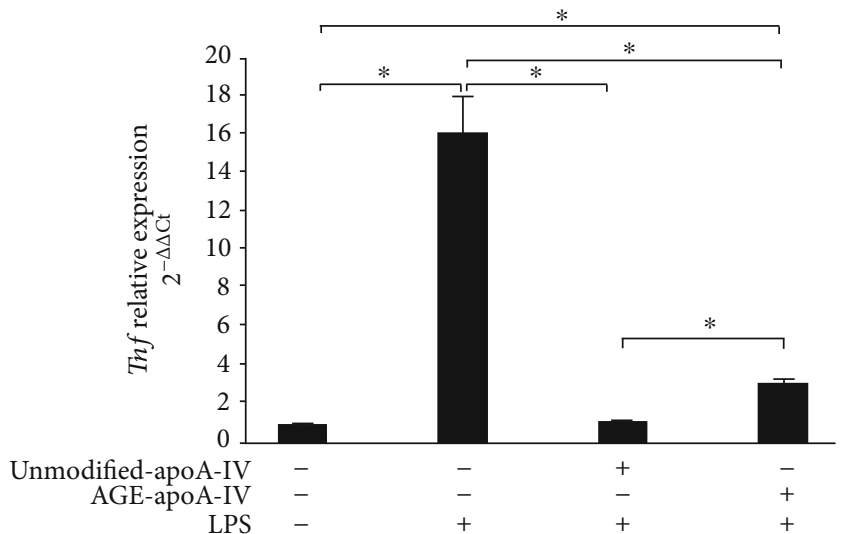

(c)

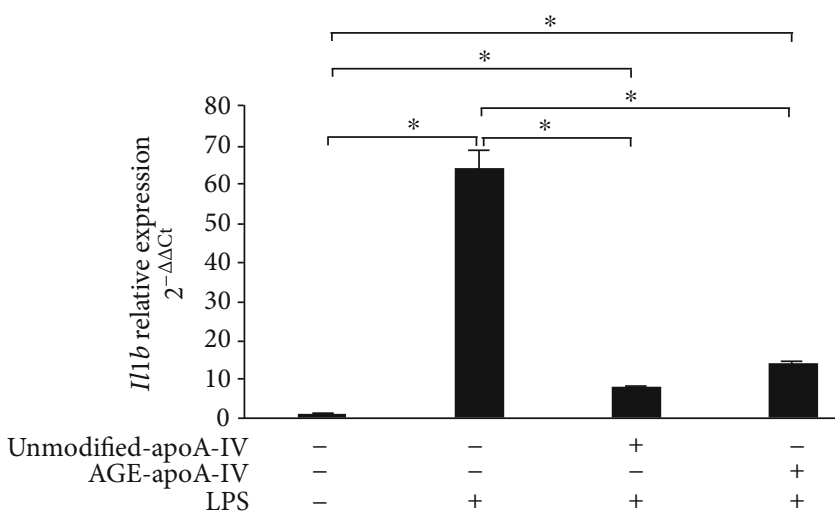

(e)

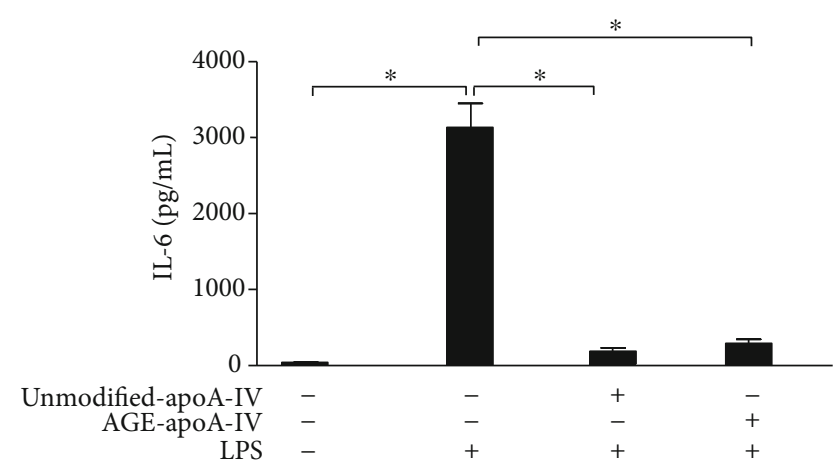

(b)

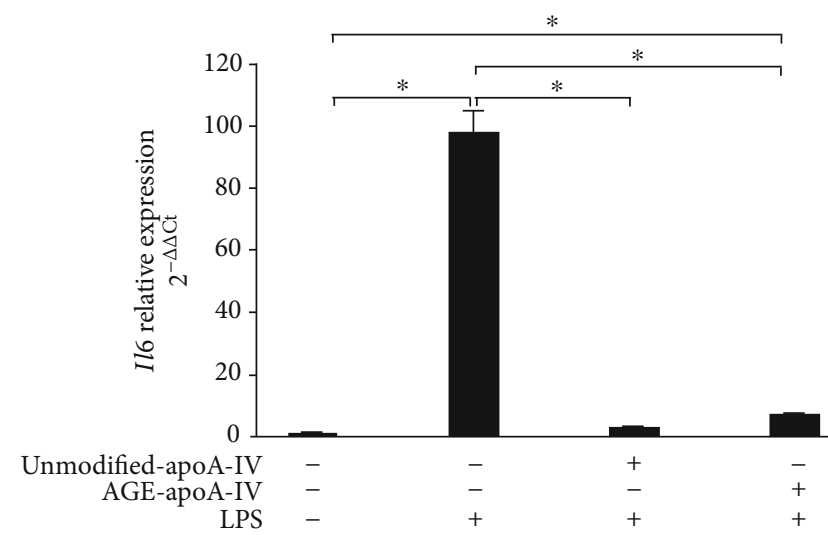

(d)

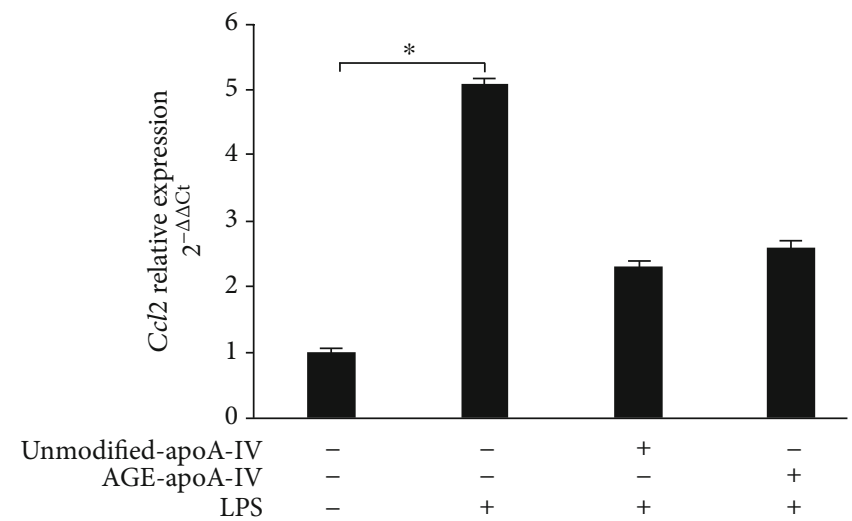

(f)

FIGURE 2: TNF-alpha and IL-6 secretion and Tnf, Il6, Illb, and Ccl2 mRNA expression by macrophages treated with unmodified or AGE-apoA-IV and further stimulated with LPS. Bone marrow-derived macrophages (BMDMs) were overloaded with acetylated LDL $(50 \mu \mathrm{g} / \mathrm{mL})$ and incubated with unmodified or AGE-apoA-IV $(n=9)$. Control incubations were kept in DMEM/FAFA alone. After washing, macrophages were stimulated for $24 \mathrm{~h}$ with $1 \mu \mathrm{g} / \mathrm{mL}$ of LPS. TNF-alpha and IL-6 secretion were quantified by ELISA ( $\mathrm{a}$ and b). Gene expression ( $-\mathrm{f}$ ) was determined by RT-qPCR as described in Material and Methods section. Data are representative of 3 independent experiments (mean $\pm \mathrm{SD} ;{ }^{*} p<0.05$ ).

\section{Results}

3.1. Pyralline and Carboxymethyllysine Content in Glycolaldehyde Modified apoA-IV. ApoA-IV was incubated with increasing concentrations of $\operatorname{GAD}(0.25,0.5$, and $1 \mathrm{mM}$ ), and AGE formation was assessed by LC-MS/MS. As shown in Figure 1, there was a dose-dependent generation of PYR (Figure 1(a)) and CML (Figure 1(b)) in apoA-IV.
3.2. AGE-apoA-IV Maintains Its Ability to Inhibit Inflammation but Is Less Efficient than Unmodified-apoA$I V$. The ability of AGE-apoA-IV to inhibit macrophage inflammation elicited by LPS was investigated. Incubation with LPS increased the secretion of TNF-alpha and IL-6 in BMDMs by 56-fold (Figure 2(a)) and 123-fold (Figure 2(b)), respectively. Preincubation of the BMDMs with unmodifiedapoA-IV inhibited the increase in TNF-alpha and IL-6 
secretion by $96 \pm 0.9 \%$ and $94 \pm 0.8 \%$, respectively. TNFalpha secretion was inhibited by $76 \pm 10 \%$ in BMDMs that were preincubated with AGE-apoA-IV, although this effect was less compared to unmodified-apoA-IV. AGE-apoA-IV inhibited IL-6 secretion as effectively as unmodified-apoAIV. These results indicate that advanced glycation minimally impairs the anti-inflammatory properties of apoAIV. This was confirmed by measuring mRNA levels of Tnf (Figure 2(c)) and Il6 (Figure 2(d)).

Incubation with LPS also increased interleukin-1 beta (Illb) (Figure 2(e)) and Ccl2 (that encodes the chemokine $\mathrm{c}-\mathrm{c}$ motif ligand $2 /$ monocyte chemotactic protein; MCP-1) mRNA levels (Figure 2(f)), 64-fold and 5-fold, respectively. The LPS-mediated increase in $I l 1 b$ was reduced by $87 \pm 7.2 \%$ in BMDMs that were preincubated with unmodified-apoA-IV and by $73 \pm 17.5 \%$ in BMDMs that were preincubated with AGE-apoA-IV (Figure 2(e)). No changes were observed in the expression of $\mathrm{Ccl} 2$ (Figure 2(f)).

LPS interacts with TLR-4 at the macrophage cell surface, triggering increased expression of the myeloid differentiation primary response gene 88 (Myd88) and tumor necrosis factor receptor-associated factor 6 (Traf6) signaling that leads to the production of inflammatory mediators. Tlr 4 mRNA levels were not changed in cells incubated with LPS alone or preincubated with unmodified-apoA-IV prior to LPS. AGE-apoAIV reduced Tlr 4 mRNA levels by $16 \pm 13 \%$ in macrophages that were incubated with LPS as compared to unmodifiedapoA-IV (Figure 3(a), $p<0.05$ ). Incubation with LPS increased Traf6 mRNA levels by 1.6-fold compared to control BMDMs (Figure 3(b)). Preincubation of BMDMs with unmodified or AGE-apoA-IV reduced the LPS-mediated increase in Traf6 expression by $41 \pm 17 \%$ and $44 \pm 24 \%$, respectively (Figure 3(b)). Myd88 mRNA levels were surprisingly increased by $50 \pm 35 \%$ compared to control in BMDMs that were preincubated with unmodified-apoA-IV. Incubation with LPS or LPS plus AGE-apoA-IV did not affect BMDM Myd88 mRNA levels (Figure 3(c)). mRNA levels of the final intracellular effectors of the inflammatory LPS signaling, $N f k b$ and Rela, were significantly increased in LPS-treated BMDMs. Cells that had been preincubated with unmodified or AGE-apo-IV reduced the LPS-elicited increase in $N f k b$ mRNA levels by $32 \pm 26 \%$ and $41 \pm 7 \%$, respectively, $(p<0.05)$, while Rela mRNA levels were reduced by $27 \pm 15 \%$ and $34 \pm 12 \%$, respectively, $(p<0.05)$ compared to cells incubated with LPS alone (Figures 3(d) and $3(\mathrm{e}))$.

LPS also activates the janus kinase 2/signal transducer and activator of transcription 3 (JAK2/STAT3) pathway. Incubation with LPS increased the Jak2 mRNA level in BMDMs by 5 -fold. Jak2 mRNA levels were reduced by $69 \pm 2 \%$ and $42 \pm 26 \%,(p<0.05)$ in BMDMs that were preincubated, respectively, with unmodified and AGEapoA-IV (Figure 3(f)). Compared to control cells, incubation of BMDMs with LPS alone and unmodified-apoA-IV plus LPS increased Stat3 mRNA levels by 1.3-fold and 1.4fold, respectively $(p<0.05)$ (Figure $3(\mathrm{~g}))$. On the other hand, preincubation with AGE-apoA-IV reduced Stat3 mRNA levels in LPS-activated HMDMs by $21 \pm 13 \%$ and $25 \pm 12 \%$ as compared, respectively, to LPS and unmodified-apoA-IV plus LPS $(p<0.05)$ (Figure $3(\mathrm{~g}))$. These results show that AGE-apoA-IV is able to inhibit the inflammatory signaling and proinflammatory cytokine production in LPSstimulated BMDMs.

3.3. Unmodified and AGE-apoA-IV Reduce Ddost but Do Not Affect Ager Expression. The mRNA level of the receptor for AGEs, RAGE (Ager), was unaffected by LPS or by preincubation with unmodified or AGE-apoA-IV (Figure 4(a)). On the other hand, Ddost, the gene that encodes AGER-1 (another AGE receptor that antagonizes RAGE signaling) was increased by 1.3-fold in BMDMs that had been incubated with LPS compared to control $(p<0.05)$ and downregulated by preincubation with unmodified-apoA-IV $(13 \pm 19 \%, p<$ $0.05)$ or AGE-apoA-IV $(27 \pm 11 \%, p<0.05)$ compared to cells incubated with LPS alone (Figure 4(b)).

3.4. AGE-apoA-IV Does Not Affect ABCA-1 Protein Expression or Cholesterol Efflux. As shown in Figure 5(a), BMDM ABCA-1 protein levels were not affected by incubation with unmodified-apoA-IV or AGE-apoA-IV. In addition, the advanced glycation of apoA-IV did not change its ability in accepting excess cholesterol (Figure 5(b)).

3.5. AGE-apoA-IV Is Unable to Prevent the Reduction in Abcal and Abcgl mRNA Induced by LPS. Incubation with LPS reduced $A b c a 1$ and $A b c g 1$ mRNA levels by $28 \pm 19 \%$ and $32 \pm 16 \%$, respectively (Figures 6(a) and 6(b)). This reduction in $A b c a 1$ and $A b c g 1$ mRNA was prevented by preincubation of the cells with unmodified-apoA-IV, but not with AGE-apoA-IV (Figures 6(a) and 6(b)). No changes were observed in the Scarb1 (SR-BI) gene expression elicited by LPS, and this was equally observed in incubations with unmodified and modified apoA-IV, respectively (Figure 6(c)). LXR alpha and beta, that are encoded by Nr1h3 and Nr1h2, and control Abcal and Abcg1 gene transcription were unaltered by LPS or unmodified and AGE-apoA-IV (Figures 6(d) and 6(e)).

\section{Discussion}

Chemical alterations of HDL apolipoproteins, including their nonenzymatic glycation by reactive $\alpha$-oxoaldehydes such as methylglyoxal, glycolaldehyde, and glyoxal, are detrimental to their function and role in atheroprotection $[36,38,40,41]$. Advanced glycation is independently related to cardiovascular disease, by inducing oxidative and inflammatory stress and disturbing the flux of cholesterol from the artery wall to the liver in the reverse cholesterol transport pathway. This may contribute to atherogenesis in diabetes mellitus (DM), chronic kidney disease, and inflammatory diseases [49-52].

In this study, it was investigated the effect of advanced glycation of apoA-IV on LPS-induced inflammation and the expression of genes that modulate cholesterol efflux in macrophages. It has been shown in macrophages that LPS represses Abcal, Abcg1, and Scarb1 gene expression [53-55]. It is postulated that the effect of LPS on Abcal is based on NF- $\kappa \mathrm{B}$ activation that induces proinflammatory 


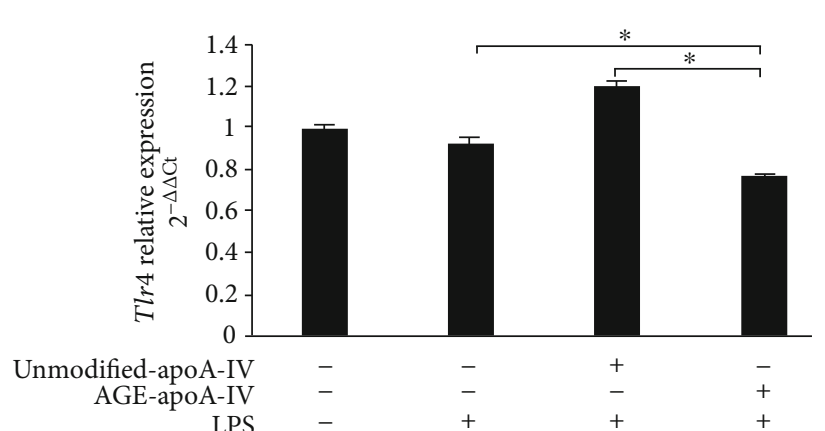

(a)

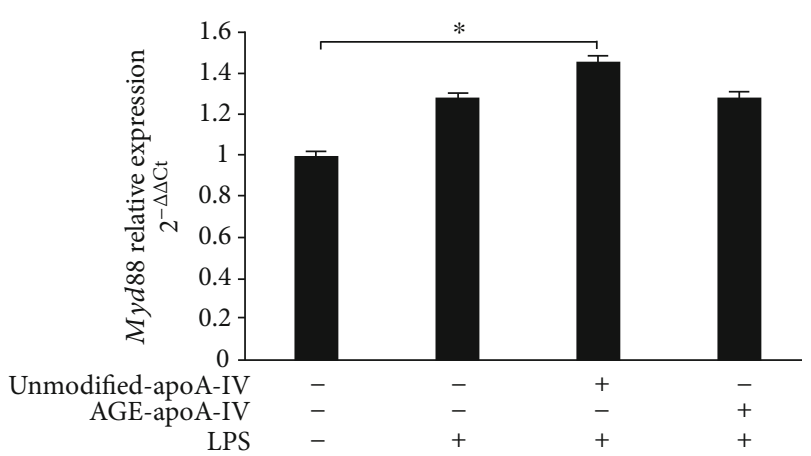

(c)

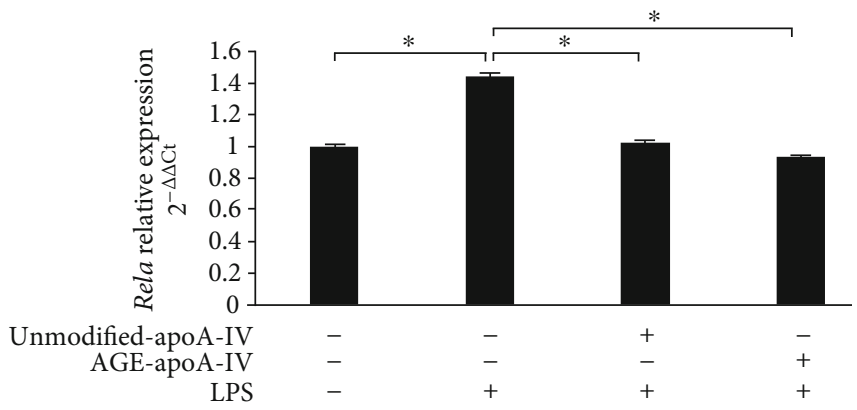

(e)

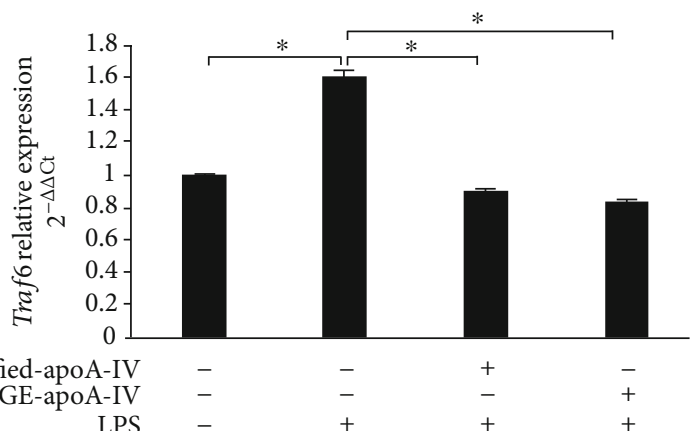

(b)

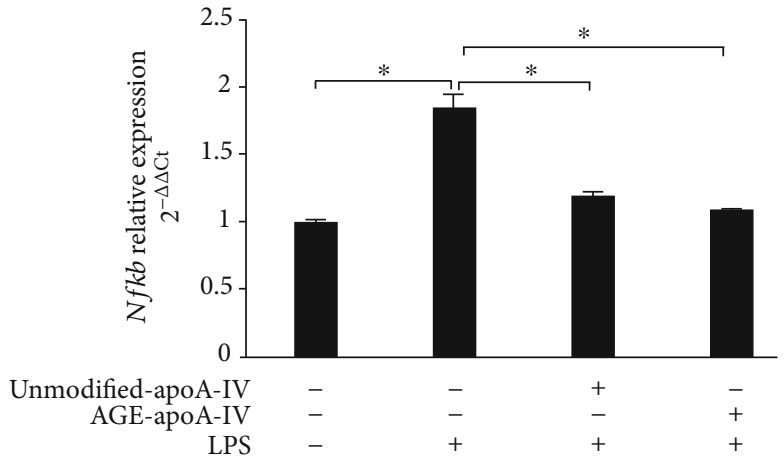

(d)

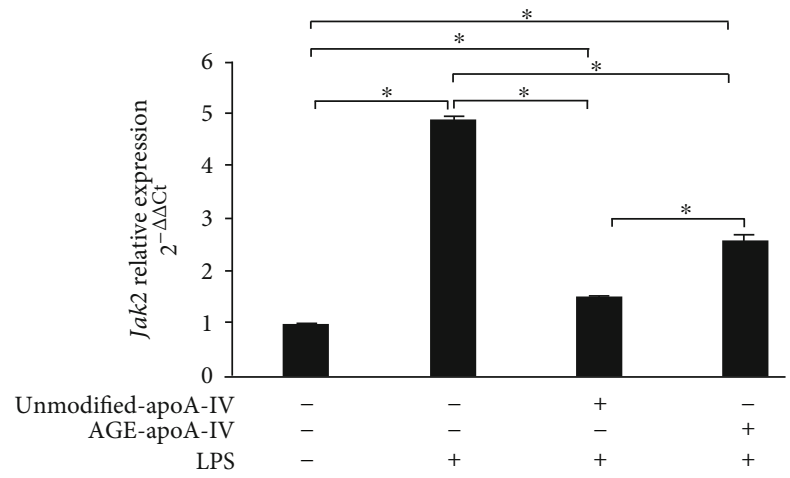

(f)

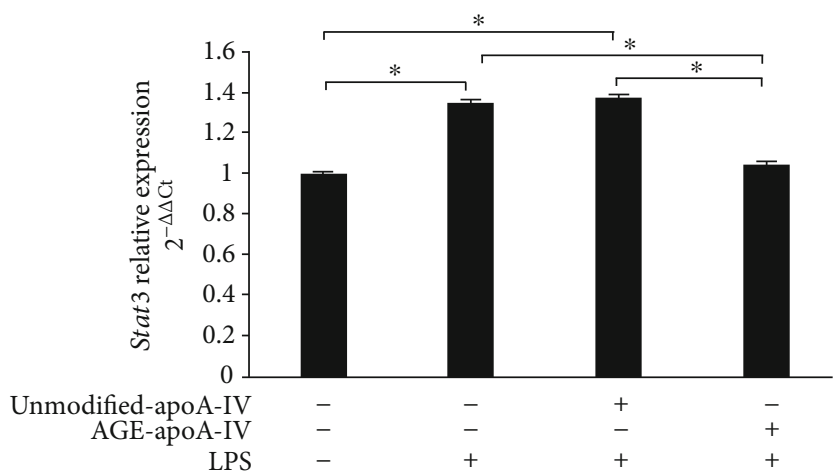

(g)

Figure 3: Tlr4, Traf6, Myd88, Nfkb, Rela, Jak2, and Stat3 expression by macrophages treated with unmodified or AGE-apoA-IV and further stimulated with LPS. Bone marrow-derived macrophages (BMDMs) were overloaded with acetylated LDL (50 $\mu \mathrm{g} / \mathrm{mL})$ and incubated with unmodified or AGE-apoA-IV. After washing, macrophages were stimulated for $24 \mathrm{~h}$ with $1 \mu \mathrm{g} / \mathrm{mL}$ of LPS $(n=9)$. Gene expression was determined by RT-qPCR as described in Material and Methods section. Data are representative of 3 independent experiments (mean $\pm \mathrm{SD},{ }^{*} p<0.05$ ). 


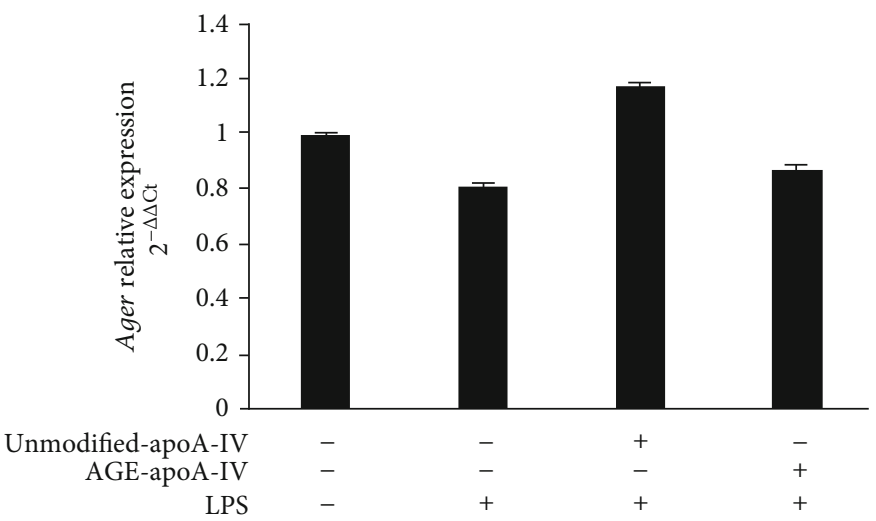

(a)

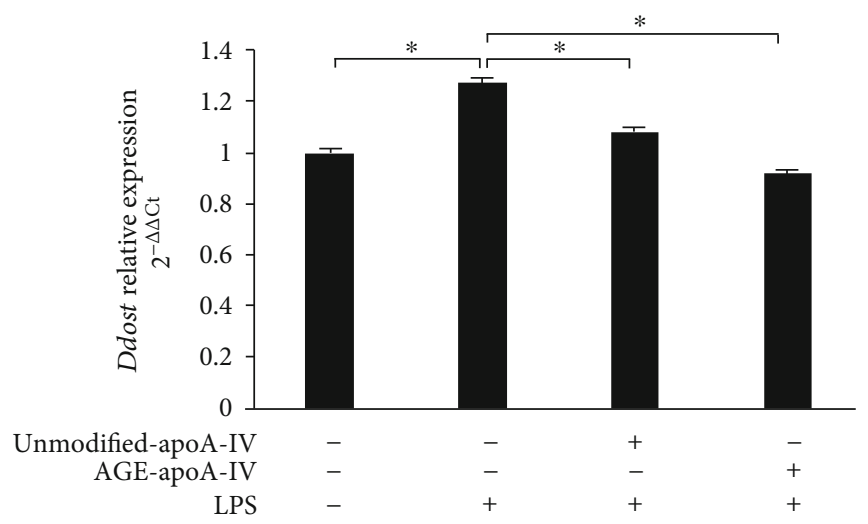

(b)

FIgURE 4: Ager and Ddost expression by macrophages treated with unmodified or AGE-apoA-IV and further stimulated with LPS. Bone marrow-derived macrophages (BMDMs) were overloaded with acetylated LDL $(50 \mu \mathrm{g} / \mathrm{mL})$ and incubated with unmodified or AGE-apoAIV. After washing, macrophages were stimulated for $24 \mathrm{~h}$ with $1 \mu \mathrm{g} / \mathrm{mL}$ of LPS $(n=9)$. Gene expression was determined by RT-qPCR as described in Material and Methods section. Data are representative of 3 independent experiments $\left(\right.$ mean $\left.\pm S D,{ }^{*} p<0.05\right)$.

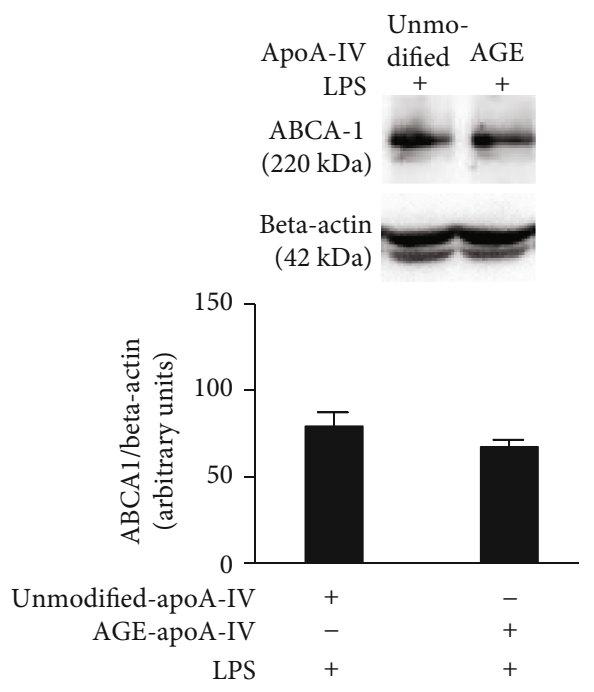

(a)

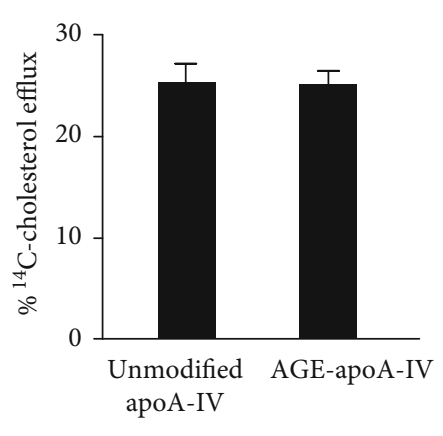

(b)

FIGURE 5: ABCA-1 expression and ${ }^{14} \mathrm{C}$-cholesterol efflux in macrophages treated with unmodified and AGE-apoA-IV (a). Bone marrowderived macrophages (BMDM) were overloaded with acetylated LDL $(50 \mu \mathrm{g} / \mathrm{mL})$ and incubated with unmodified or AGE-apoA-IV for $48 \mathrm{~h}$. After washing, macrophages were stimulated for $24 \mathrm{~h}$ with $1 \mu \mathrm{g} / \mathrm{mL}$ of LPS. The ABCA-1 protein level was determined by immunoblot $(n=3)$ (b). BMDMs were overloaded with acetylated LDL $(50 \mu \mathrm{g} / \mathrm{mL})$ and ${ }^{14} \mathrm{C}$-cholesterol for $48 \mathrm{~h}$. After maintenance in equilibrium medium, cells were incubated with unmodified or AGE-apoA-IV as cholesterol acceptors $(n=6)$. Cholesterol efflux was calculated as ${ }^{14} \mathrm{C}$-cholesterol in medium $/{ }^{14} \mathrm{C}$-cholesterol in medium $+{ }^{14} \mathrm{C}$-cholesterol in cells $\times 100$. Basal efflux was determined in incubations with DMEM containing fatty acid-free albumin that was subtracted from those with apoA-IV. Data are representative of 3 independent experiments (mean $\pm \mathrm{SD}$ ) and were compared by the Student $t$ test.

cytokine secretion and the expression of miR33 that represses the expression of $A b c a 1$ and subsequently diminishes cholesterol efflux [54].

The production of proinflammatory mediators associated with cell injury induced by LPS involves the activation of the TLR-4/Myd88/Traf6 signal transduction pathway and the downstream effector NF- $\kappa \mathrm{B}$, as well as the JAK/STAT and MAPK pathways [56-58]. In agreement with previous studies $[8,9,22]$, our observations confirmed that
unmodified-apoA-IV removes cholesterol from BMDMs and alleviates the LPS-induced inflammatory burst. This leads to diminished expression and secretion of proinflammatory cytokines as well as genes involved in LPS signaling such as Tlr4, Traf6, Jak2, Stat3, Nfkb, and Rela, while prevents the reduction induced by LPS in the expression Abcal and $A b c g 1$ genes.

Interestingly, AGE-apoA-IV significantly inhibited proinflammatory cytokine secretion and reduced mRNA 


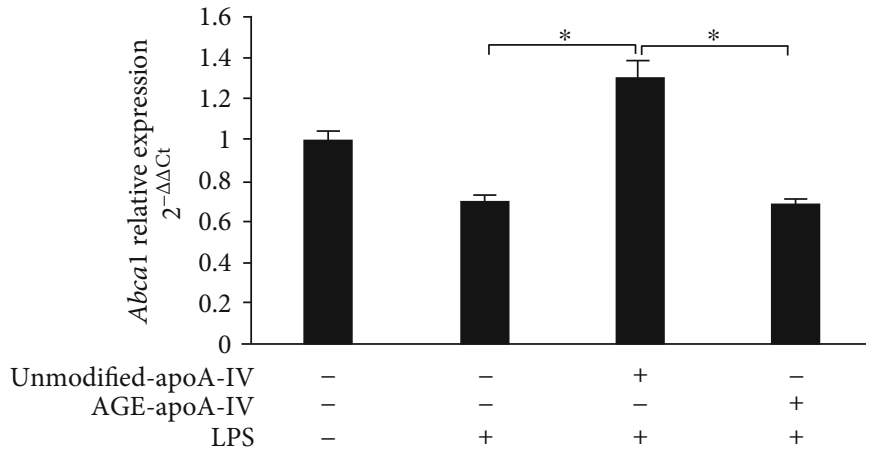

(a)

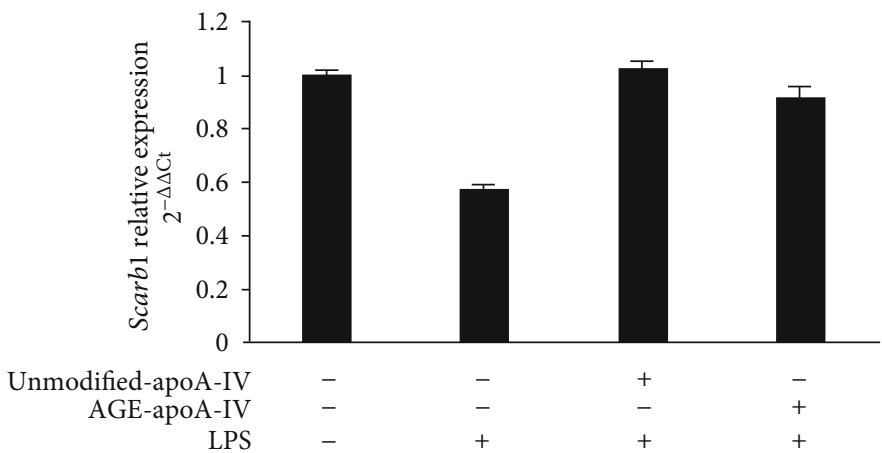

(c)

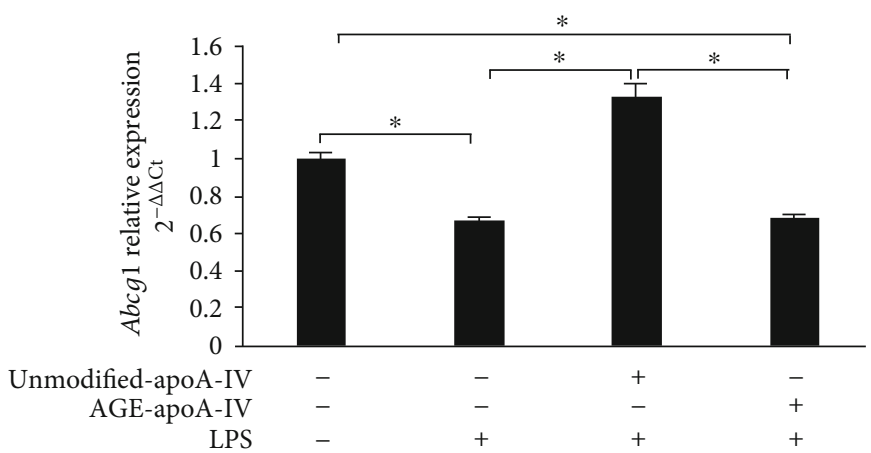

(b)

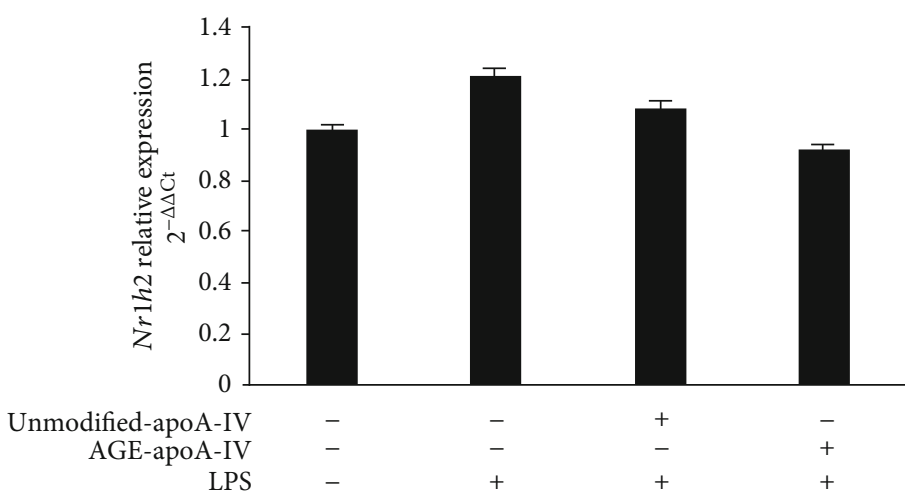

(e)

FIGURE 6: Abca1, Abcg1, Scarb1, Nr1h3, and Nr1h2 mRNA expression in macrophages treated with unmodified or AGE-apoA-IV and further stimulated with LPS. Bone marrow-derived macrophages (BMDMs) were overloaded with acetylated LDL ( $50 \mu \mathrm{g} / \mathrm{mL})$ and incubated with unmodified or AGE-apoA-IV. After washing, macrophages were stimulated for $24 \mathrm{~h}$ with $1 \mu \mathrm{g} / \mathrm{mL}$ of LPS $(n=9)$. Gene expression was determined by RT-qPCR as described in Material and Methods section. Data are representative of 3 independent experiments (mean \pm SD, $\left.{ }^{*} p<0.05\right)$ and were compared by ANOVA and Tukey's post-test.

levels of TNF-alpha and IL-6 in LPS-treated cells, nonetheless, less effectively than unmodified-apoA-IV. This is in contrast to the findings of Dai et al. (2017) [39], who reported increased expression and secretion of proinflammatory cytokines in human aortic endothelial cells (HAECs) treated with AGE-apoA-IV. These authors also showed that nonenzymatically glycated apoA-IV enhanced atherosclerotic lesion development in apoE knockout mice. These conflicting results may be related to the fact that Dai et al. (2017) [39] used concentration of $20 \mathrm{mM}$ glyoxal to modify apoA-IV compared to $1 \mathrm{mM}$ glycolaldehyde in the present study.
Although levels of proteins involved in TLR-4 signaling were not addressed by immunoblot in the present investigation, the expression of Tlr4, Traf6, Nfkb, Rela, Jak2, and Stat3 genes was significantly reduced by AGE-apoA-IV in cells challenged by LPS.

The ability of glycated apoA-IV by itself to efflux cholesterol from macrophages was conserved. This is consistent with what has been reported previously for the efflux of cholesterol by nonenzymatically glycated apoA-I from the J774 macrophage cell line [59], but is contrary to others that showed reduction in cholesterol efflux mediated by glycated apoA-I in THP-1 and J774 macrophages [36, 38, 60]. 
Although preserving its ability in reducing the LPSelicited inflammation, AGE-apoA-IV was unable to prevent the reduction in Abcal and Abcg1 gene expression as compared to unmodified-apoA-IV. The exact mechanisms by which this effect occurs were not demonstrated at this point and require further investigation. Since $A b c a 1$ and $A b c g 1$ mRNAs were reduced in cells incubated with LPS alone or with LPS plus AGE-apoA-IV, it is possible to consider that cholesterol efflux will be reduced by compromising the final amount of $\mathrm{ABC}$ protein.

CML is the major AGE formed in vivo, and it is present in atherosclerotic lesions [61]. Although different types of AGEs seem to bind to different domains of RAGE, which can interfere with their receptor affinity, CML binds to the V domain, while PYR, argpyrimidine, and pentosidine interact with the $\mathrm{C}$ domain $[62,63]$. However, studies that have evaluated the effect of the interaction of specific AGEs with RAGE are still contradictory and limited to CML. While some investigators have shown that CML is an excellent RAGE ligand that increases inflammatory stress $[64,65]$, others have suggested the opposite $[66,67]$. Additional studies are needed to identify and evaluate the affinity of different types of AGEs with RAGE and the resulting physiopathology.

Ddost encodes for AGER1, an AGE receptor whose expression is induced during glycoxidative and inflammatory stress allowing antagonism to the deleterious signaling of the AGE-RAGE axis [68]. In this investigation, we found reduction in Ddost mRNA levels in cells preincubated with unmodified and AGE-apoA-IV prior to LPS. This may be likely related to the capacity of both unmodified and glycated apoA-IV in inhibiting the inflammation elicited by LPS.

The current results are consistent with previous data from our group for isolated HDL [69]. Preincubation with HDL minimized the inflammatory effects of LPS in macrophages, although the exact mechanisms that are elicited by HDL or apo-IV, despite not being present during the LPS treatment, are not completely understood and worthy of further investigation.

\section{Conclusion}

In conclusion, although maintaining its anti-inflammatory activity, AGE-apoA-IV loses its ability in counteracting LPS effects on Abcal and Abcg1 genes. This may contribute to atherogenesis in DM and other metabolic conditions that are associated with increased carbonyl stress. Future studies dealing with animal models susceptible to atherosclerosis treated with unmodified and AGE-apoA-IV will help to understand the antiatherogenic role of this apolipoprotein in the context of diabetes mellitus and glycoxidative stress.

\section{Data Availability}

No data were used to support this study.

\section{Conflicts of Interest}

The authors declare that there is no conflict of interest regarding the publication of this paper.

\section{Acknowledgments}

The authors are thankful to Laboratórios de Investigação Médica e Fundação Faculdade de Medicina for their continuous support and to Prof. Shinji Yokoyama (MAB Institute, Japan) for providing the ABCA-1 antibody. This work was supported by Fundação de Amparo à Pesquisa do Estado de São Paulo (FAPESP); grants 2016/15603-0 to MP, MLCCG, and UFM; 2015/21072-5 to MP; 2013/23392-1 and 2013/02854-7 to LSO; and 2013/26256-1 to RTI. This study was financed in part by the Coordenação de Aperfeiçoamento de Pessoal de Nível Superior-Brasil (CAPES)-Finance Code 001, to PRP. MP, MLCCG, and UFB are recipients of a grant from Conselho Nacional de Desenvolvimento Científico e Tecnológico (CNPq).

\section{References}

[1] Emerging Risk Factors Collaboration, E. di Angelantonio, N. Sarwar et al., "Major lipids, apolipoproteins, and risk of vascular disease," Journal of the American Medical Association, vol. 302, no. 18, pp. 1993-2000, 2009.

[2] P. J. Barter, M. Caulfield, M. Eriksson et al., "Effects of torcetrapib in patients at high risk for coronary events," The New England Journal of Medicine, vol. 357, no. 21, pp. 2109-2122, 2007.

[3] G. G. Schwartz, A. G. Olsson, M. Abt et al., "Effects of dalcetrapib in patients with a recent acute coronary syndrome," The New England Journal of Medicine, vol. 367, no. 22, pp. 20892099, 2012.

[4] B. F. Voight, G. M. Peloso, M. Orho-Melander et al., "Plasma HDL cholesterol and risk of myocardial infarction: a mendelian randomisation study," Lancet, vol. 380, no. 9841, pp. 572-580, 2012.

[5] P. J. Barter and K. A. Rye, "HDL cholesterol concentration or HDL function: which matters?," European Heart Journal, vol. 38, no. 32, pp. 2487-2489, 2017.

[6] A. Rohatgi, A. Khera, J. D. Berry et al., "HDL cholesterol efflux capacity and incident cardiovascular events," The New England Journal of Medicine, vol. 371, no. 25, pp. 2383-2393, 2014.

[7] K. A. Rye and P. Barter, "Regulation of high-density lipoprotein metabolism," Circulation Research, vol. 114, no. 1, pp. 143-156, 2014.

[8] T. Vowinkel, M. Mori, C. F. Krieglstein et al., "Apolipoprotein A-IV inhibits experimental colitis," The Journal of Clinical Investigation, vol. 114, no. 2, pp. 260-269, 2004.

[9] D. Recalde, M. A. Ostos, E. Badell et al., "Human apolipoprotein A-IV reduces secretion of proinflammatory cytokines and atherosclerotic effects of a chronic infection mimicked by lipopolysaccharide," Arteriosclerosis, Thrombosis, and Vascular Biology, vol. 24, no. 4, pp. 756-761, 2004.

[10] M. A. Ostos, M. Conconi, L. Vergnes et al., "Antioxidative and antiatherosclerotic effects of human apolipoprotein A-IV in apolipoprotein E-deficient mice," Arteriosclerosis, Thrombosis, and Vascular Biology, vol. 21, no. 6, pp. 1023-1028, 2001.

[11] W. M. R. Wong, A. B. Gerry, W. Putt et al., "Common variants of apolipoprotein A-IV differ in their ability to inhibit low density lipoprotein oxidation," Atherosclerosis, vol. 192, no. 2, pp. 266-274, 2007.

[12] X. R. Xu, Y. Wang, R. Adili et al., "Apolipoprotein A-IV binds $\alpha \mathrm{IIb} \beta 3$ integrin and inhibits thrombosis," Nature Communications, vol. 9, no. 1, p. 3608, 2018. 
[13] R. B. Weinberg, J. W. Gallagher, M. A. Fabritius, and G. S. Shelness, "ApoA-IV modulates the secretory trafficking of apoB and the size of triglyceride-rich lipoproteins," Journal of Lipid Research, vol. 53, no. 4, pp. 736-743, 2012.

[14] F. Wang, A. B. Kohan, T. L. Kindel et al., "Apolipoprotein A-IV improves glucose homeostasis by enhancing insulin secretion," Proceedings of the National Academy of Sciences of the United States of America, vol. 109, no. 24, pp. 9641-9646, 2012.

[15] X. Li, M. Xu, F. Wang et al., "Apolipoprotein A-IV reduces hepatic gluconeogenesis through nuclear receptor NR1D1," The Journal of Biological Chemistry, vol. 289, no. 4, pp. 2396-2404, 2014.

[16] X. Li, M. Xu, F. Wang et al., "Interaction of apoA-IV with NR4A1 and NR1D1 represses G6Pase and PEPCK transcription: nuclear receptor-mediated downregulation of hepatic gluconeogenesis in mice and a human hepatocyte cell line," PLoS One, vol. 10, no. 11, 2015.

[17] X. Li, F. Wang, M. Xu, P. Howles, and P. Tso, “ApoA-IV improves insulin sensitivity and glucose uptake in mouse adipocytes via PI3K-Akt signaling," Scientific Reports, vol. 7, 2017.

[18] K. Fujimoto, K. Fukagawa, T. Sakata, and P. Tso, "Suppression of food intake by apolipoprotein A-IV is mediated through the central nervous system in rats," Journal of Clinical Investigation, vol. 91, no. 4, pp. 1830-1833, 1993.

[19] L. Shen, C. C. Lo, L. A. Woollett, and M. Liu, “Apolipoprotein A-IV exerts its anorectic action through a PI3K/Akt signaling pathway in the hypothalamus," Biochemical and Biophysical Research Communications, vol. 494, no. 1-2, pp. 152-157, 2017.

[20] A. Steinmetz and G. Ultermann, "Activation of lecithin:cholesterol acyltransferase by human apolipoprotein A-IV," The Journal of Biological Chemistry, vol. 260, no. 4, pp. 22582264, 1985.

[21] V. Guyard-Dangremont, L. Lagrost, and P. Gambert, "Comparative effects of purified apolipoproteins A-I, A-II and AIV on cholesteryl ester transfer protein activity," Journal of Lipid Research, vol. 35, no. 6, pp. 982-992, 1994.

[22] A. Steinmetz, R. Barbaras, N. Ghalim, V. Clavey, J. C. Fruchart, and G. Ailhaud, "Human apolipoprotein A-IV binds to apolipoprotein A-I/A-II receptor sites and promotes cholesterol efflux from adipose cells," The Journal of Biological Chemistry, vol. 265, no. 14, pp. 7859-7863, 1990.

[23] M. Gomaraschi, W. E. Putt, S. Pozzi et al., "Structure and function of the apoA-IV T347S and Q360H common variants," Biochemical and Biophysical Research Communications, vol. 393, no. 1, pp. 126-130, 2010.

[24] N. Fournier, V́. Atger, J. L. Paul et al., "Human apoA-IV overexpression in transgenic mice induces cAMP-stimulated cholesterol efflux from J774 macrophages to whole serum," Arteriosclerosis, Thrombosis, and Vascular Biology, vol. 20, no. 5, pp. 1283-1292, 2000.

[25] A. Duka, P. Fotakis, D. Georgiadou et al., “ApoA-IV promotes the biogenesis of apoA-IV-containing HDL particles with the participation of ABCA1 and LCAT," Journal of Lipid Research, vol. 54, no. 1, pp. 107-115, 2013.

[26] K. Alwaili, D. Bailey, Z. Awan et al., "The HDL proteome in acute coronary syndromes shifts to an inflammatory profile," Biochimica et Biophysica Acta, vol. 1821, no. 3, pp. 405-415, 2012.

[27] F. Kronenberg, M. Stühlinger, E. Trenkwalder et al., "Low apolipoprotein A-IV plasma concentrations in men with coronary artery disease," Journal of the American College of Cardiology, vol. 36, no. 3, pp. 751-757, 2000.

[28] N. Duverger, G. Tremp, J. M. Caillaud et al., "Protection against atherogenesis in mice mediated by human apolipoprotein A-IV," Science, vol. 273, no. 5277, pp. 966-968, 1996.

[29] R. D. Cohen, L. W. Castellani, J. H. Qiao, B. J. Van Lenten, A. J. Lusis, and K. Reue, "Reduced aortic lesions and elevated high density lipoprotein levels in transgenic mice overexpressing mouse apolipoprotein A-IV," Journal of Clinical Investigation, vol. 99, no. 8, pp. 1906-1916, 1997.

[30] J. Qu, C. W. Ko, P. Tso, and A. Bhargava, “Apolipoprotein AIV: A Multifunctional Protein Involved in Protection against Atherosclerosis and Diabetes," Cells, vol. 8, no. 4, p. 319, 2019.

[31] A. Lapolla, M. Brioschi, C. Banfi et al., "Nonenzymatically glycated lipoprotein apoA-I in plasma of diabetic and nephropathic patients," Annals of the New York Academy of Sciences, vol. 1126, no. 1, pp. 295-299, 2008.

[32] A. Lapolla, M. Brioschi, C. Banfi et al., "On the search for glycated lipoprotein apoA-I in the plasma of diabetic and nephropathic patients," Journal of Mass Spectrometry, vol. 43, no. 1, pp. 74-81, 2008.

[33] R. Singh, A. Barden, T. Mori, and L. Beilin, "Advanced glycation end-products: a review," Diabetologia, vol. 44, no. 2, pp. 129-146, 2001.

[34] P. J. Thornalley, "Advanced glycation end products in renal failure," Journal of Renal Nutrition, vol. 16, no. 3, pp. 178184, 2006

[35] J. Uribarri, W. Cai, O. Sandu, M. Peppa, T. Goldberg, and H. Vlassara, "Diet-derived advanced glycation end products are major contributors to the body's AGE pool and induce inflammation in healthy subjects," Annals of the New York Academy of Sciences, vol. 1043, pp. 461-466, 2005.

[36] A. Hoang, A. J. Murphy, M. T. Coughlan et al., "Advanced glycation of apolipoprotein A-I impairs its anti-atherogenic properties," Diabetologia, vol. 50, no. 8, pp. 1770-1779, 2007.

[37] D. Liu, L. Ji, M. Zhao et al., "Lysine glycation of apolipoprotein A-I impairs its anti-inflammatory function in type 2 diabetes mellitus," Journal of Molecular and Cellular Cardiology, vol. 122, pp. 47-57, 2018.

[38] J. Domingo-Espín, O. Nilsson, K. Bernfur, R. Del Giudice, and J. O. Lagerstedt, "Site-specific glycations of apolipoprotein A-I lead to differentiated functional effects on lipid-binding and on glucose metabolism," Biochimica et Biophysica Acta (BBA)Molecular Basis of Disease, vol. 1864, no. 9, pp. 2822-2834, 2018.

[39] E. Nobecourt, F. Tabet, G. Lambert et al., "Nonenzymatic Glycation impairs the Antiinflammatory properties of apolipoprotein A-I," Arteriosclerosis, Thrombosis, and Vascular Biology, vol. 30, no. 4, pp. 766-772, 2010.

[40] E. Nobecourt, M. J. Davies, B. E. Brown et al., "The impact of glycation on apolipoprotein A-I structure and its ability to activate lecithin:cholesterol acyltransferase," Diabetologia, vol. 50, no. 3, pp. 643-653, 2007.

[41] L. J. Pu, L. Lu, R. Y. Zhang et al., "Glycation of apoprotein A-I is associated with coronary artery plaque progression in type 2 diabetic patients," Diabetes Care, vol. 36, no. 5, pp. 1312-1320, 2013.

[42] Y. Dai, Y. Shen, Q. R. Li et al., "Glycated Apolipoprotein A-IV induces atherogenesis in patients with CAD in type 2 diabetes," Journal of the American College of Cardiology, vol. 70, no. 16, pp. 2006-2019, 2017. 
[43] F. R. Geronimo, P. J. Barter, K. A. Rye, A. K. Heather, K. D. Shearston, and K. J. Rodgers, "Plaque stabilizing effects of apolipoprotein A-IV," Atherosclerosis, vol. 251, pp. 39-46, 2016.

[44] D. J. Gomes, A. P. Velosa, L. S. Okuda et al., "Glycated albumin induces lipid infiltration in mice aorta independently of DM and RAS local modulation by inducing lipid peroxidation and inflammation," Journal of Diabetes and its Complications, vol. 30, no. 8, pp. 1614-1621, 2016.

[45] G. Daffu, X. Shen, L. Senatus et al., "RAGE suppresses ABCG1mediated macrophage cholesterol efflux in diabetes," Diabetes, vol. 64, no. 12, pp. 4046-4060, 2015.

[46] S. K. Basu, J. L. Goldstein, G. W. Anderson, and M. S. Brown, "Degradation of cationized low density lipoprotein and regulation of cholesterol metabolism in homozygous familial hypercholesterolemia fibroblasts," Proceedings of the National Academy of Sciences of the United States of America, vol. 73, no. 9, pp. 3178-3182, 1976.

[47] A. P. Machado, R. S. Pinto, Z. P. Moysés, E. R. Nakandakare, E. C. Quintão, and M. Passarelli, "Aminoguanidine and metformin prevent the reduced rate of HDL-mediated cell cholesterol efflux induced by formation of advanced glycation end products," The International Journal of Biochemistry \& Cell Biology, vol. 38, no. 3, pp. 392-403, 2006.

[48] K. J. Livak and T. D. Schmittgen, "Analysis of relative gene expression data using real-time quantitative PCR and the 2(Delta Delta C(T)) method," Methods, vol. 25, no. 4, pp. 402408, 2001.

[49] P. Traldi, G. Castilho, C. H. Sartori et al., "Glycated human serum albumin isolated from poorly controlled diabetic patients impairs cholesterol efflux from macrophages: an investigation by mass spectrometry," European Journal of Mass Spectrometry, vol. 21, no. 3, pp. 233-244, 2015.

[50] A. Machado-Lima, R. T. Iborra, R. S. Pinto et al., "In type 2 diabetes mellitus glycated albumin alters macrophage gene expression impairing ABCA1-mediated cholesterol efflux," Journal of Cellular Physiology, vol. 230, no. 6, pp. 1250-1257, 2015.

[51] J. T. Machado, R. T. Iborra, F. B. Fusco et al., "N-acetylcysteine prevents endoplasmic reticulum stress elicited in macrophages by serum albumin drawn from chronic kidney disease rats and selectively affects lipid transporters, ABCA-1 and ABCG-1," Atherosclerosis, vol. 237, no. 1, pp. 343-352, 2014.

[52] A. Machado-Lima, R. T. Iborra, R. S. Pinto et al., "Advanced glycated albumin isolated from poorly controlled type 1 diabetes mellitus patients alters macrophage gene expression impairing ABCA-1-mediated reverse cholesterol transport," Diabetes/Metabolism Research and Reviews, vol. 29, no. 1, pp. 66-76, 2013.

[53] Y. Park, T. X. Pham, and J. Lee, "Lipopolysaccharide represses the expression of ATP-binding cassette transporter G1 and scavenger receptor class B, type I in murine macrophages," Inflammation Research, vol. 61, no. 5, pp. 465-472, 2012.

[54] G. J. Zhao, S. L. Tang, Y. C. Lv et al., "Antagonism of betulinic acid on LPS-mediated inhibition of ABCA1 and cholesterol efflux through inhibiting nuclear factor-kappaB signaling pathway and miR-33 expression," PLoS One, vol. 8, no. 9, 2013.

[55] I. Baranova, T. Vishnyakova, A. Bocharov et al., "Lipopolysaccharide down regulates both scavenger receptor B1 and ATP binding cassette transporter A1 in RAW cells," Infection and Immunity, vol. 70, no. 6, pp. 2995-3003, 2002.

[56] Y. C. Lu, W.-C. Yeh, and P. S. Ohashi, "LPS/TLR4 signal transduction pathway," Cytokine, vol. 42, no. 2, pp. 145151, 2008.
[57] S. H. Kim, S. Y. Park, Y. L. Park, D. S. Myung, J. S. Rew, and Y. E. Joo, "Chlorogenic acid suppresses lipopolysaccharide induced nitric oxide and interleukin- $1 \beta$ expression by inhibiting JAK2/STAT3 activation in RAW264.7 cells," Molecular Medicine Reports, vol. 16, no. 6, pp. 9224-9232, 2017.

[58] Q. Yu, K. W. Zeng, X. L. Ma, Y. Jiang, P. F. Tu, and X. M. Wang, "Ginsenoside Rk1 suppresses pro-inflammatory responses in lipopolysaccharide-stimulated RAW264.7 cells by inhibiting the Jak2/Stat3 pathway," Chinese Journal of Natural Medicines, vol. 15, no. 10, pp. 751-757, 2017.

[59] B. E. Brown, E. Nobecourt, J. Zeng, A. J. Jenkins, K. A. Rye, and M. J. Davies, "Apolipoprotein A-I glycation by glucose and reactive aldehydes alters phospholipid affinity but not cholesterol export from lipid-laden macrophages," PLoS One, vol. 8 , no. $5,2013$.

[60] K. Matsuki, N. Tamasawa, M. Yamashita et al., "Metformin restores impaired HDL-mediated cholesterol efflux due to glycation," Atherosclerosis, vol. 206, no. 2, pp. 434-438, 2009.

[61] S. F. Yan, R. Ramasamy, Y. Naka, and A. M. Schmidt, "Glycation, inflammation, and RAGE. A scaffold for the macrovascular complications of diabetes and beyond," Circulation Research, vol. 93, no. 12, pp. 1159-1169, 2003.

[62] F. Fatchiyah, F. Hardiyanti, and N. Widodo, "Selective inhibition on RAGE-binding AGEs required by bioactive peptide alpha-S2 case in protein from goat Ethawah breed milk: study of biological modeling," Acta Informatica Medica, vol. 23, no. 2, pp. 90-96, 2015.

[63] J. Xue, V. Rai, D. Singer et al., "Advanced glycation end product recognition by the receptor for AGEs," Structure, vol. 19, no. 5, pp. 722-732, 2011.

[64] T. Kislinger, C. Fu, B. Huber et al., "N(epsilon)-(carboxymethyl)lysine adducts of proteins are ligands for receptor for advanced glycation end products that activate cell signaling pathways and modulate gene expression," The Journal of Biological Chemistry, vol. 274, no. 44, pp. 31740-31749, 1999.

[65] A. K. Holik, B. Rohm, M. M. Somoza, and V. Somoza, "N( $(\varepsilon)$ Carboxymethyllysine (CML), a Maillard reaction product, stimulates serotonin release and activates the receptor for advanced glycation end products (RAGE) in SH-SY5Y cells," Food \& Function, vol. 4, no. 7, pp. 1111-1120, 2013.

[66] T. M. Buetler, E. Leclerc, A. Baumeyer et al., "Ne-carboxymethyllysine-modified proteins are unable to bind to RAGE and activate an inflammatory response," Molecular Nutrition \& Food Research, vol. 52, no. 3, pp. 370-378, 2008.

[67] M. L. Lieuw-a-Fa, C. G. Schalkwijk, M. Engelse, and V. W. van Hinsbergh, "Interaction of Nepsilon (carboxymethyl)lysineand methylglyoxal-modified albumin with endothelial cells and macrophages. Splice variants of RAGE may limit the responsiveness of human endothelial cells to AGEs," Thrombosis and Haemostasis, vol. 95, no. 2, pp. 320-328, 2006.

[68] D. P. Santos-Bezerra, A. Machado-Lima, M. B. Monteiro et al., "Dietary advanced glycated end-products and medicines influence the expression of SIRT1 and DDOST in peripheral mononuclear cells from long-term type 1 diabetes patients," Diabetes \& Vascular Disease Research, vol. 15, no. 1, pp. 81-89, 2018.

[69] L. S. Okuda, G. Castilho, D. D. F. M. Rocco, E. R. Nakandakare, S. Catanozi, and M. Passarelli, "Advanced glycated albumin impairs HDL anti-inflammatory activity and primes macrophages for inflammatory response that reduces reverse cholesterol transport," Biochimica et Biophysica Acta, vol. 1821, no. 12, pp. 1485-1492, 2012. 


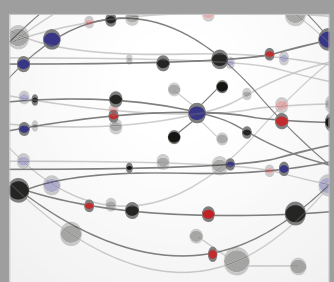

The Scientific World Journal
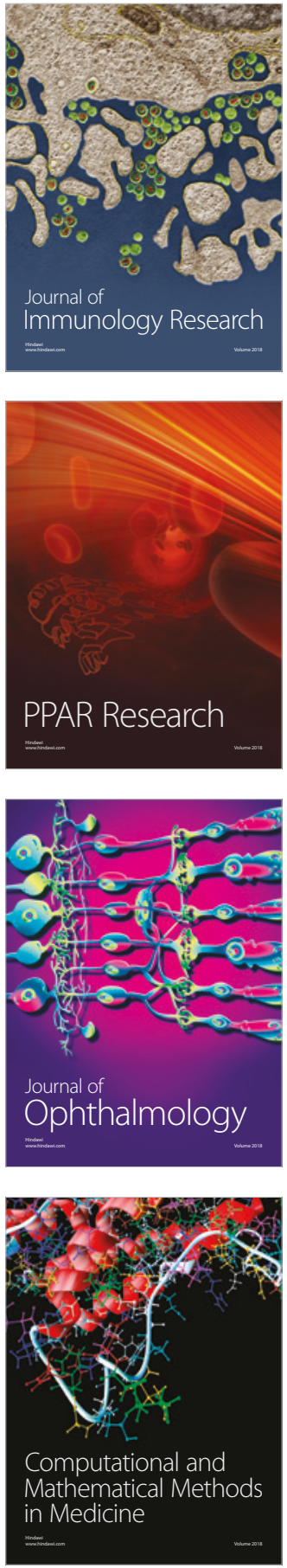

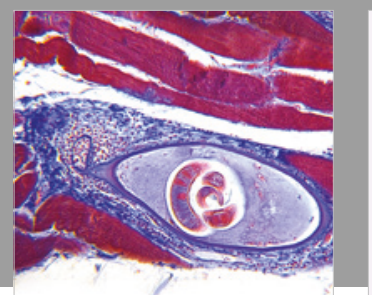

Gastroenterology Research and Practice

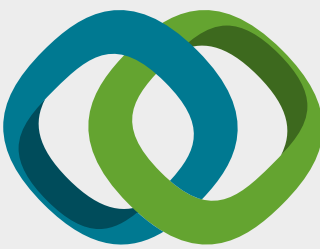

\section{Hindawi}

Submit your manuscripts at

www.hindawi.com
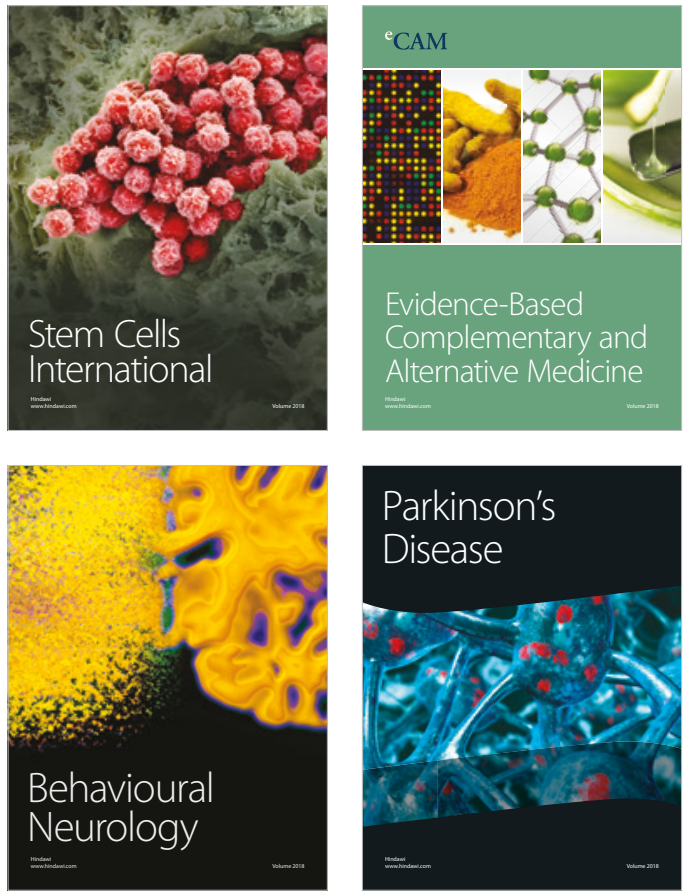

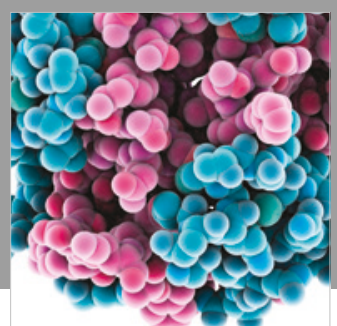

ournal of

Diabetes Research

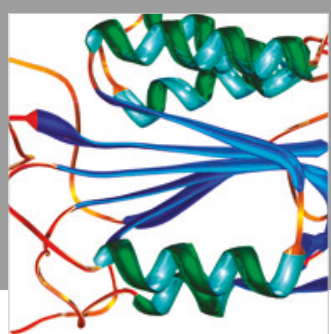

Disease Markers
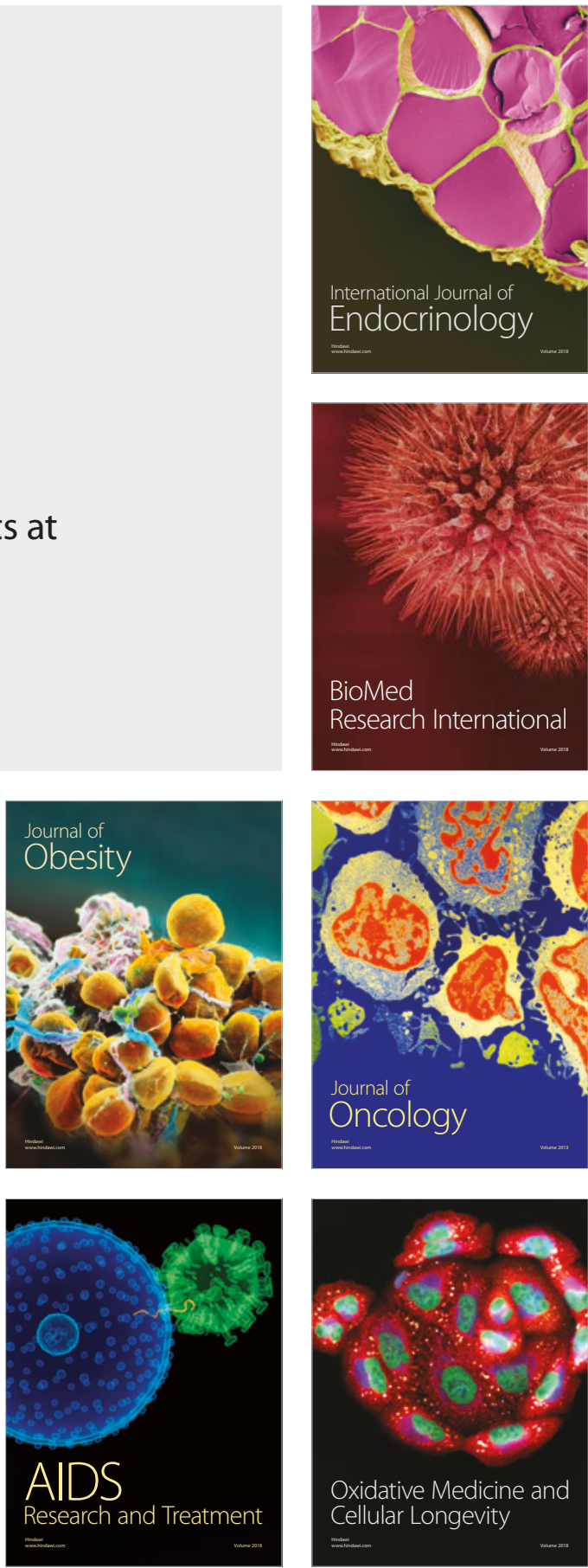